\title{
Treatment of particle/gas partitioning using level III fugacity models in a six-compartment system
}

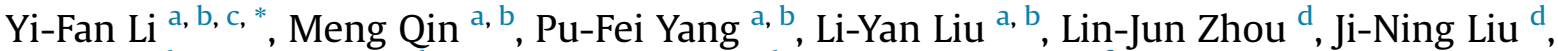 \\ Li-Li Shi ${ }^{d}$, Li-Na Qiao a, b, e, Peng-Tuan Hu ${ }^{\text {a, b }}{ }^{\text {, Chong-Guo Tian }}{ }^{\mathrm{f}}$, Anatoly Nikolaev ${ }^{\mathrm{g}}$, \\ Robie Macdonald ${ }^{\mathrm{h}}$ \\ a International Joint Research Center for Persistent Toxic Substances (IJRC-PTS), State Key Laboratory of Urban Water Resource and Environment/School of \\ Environment, Harbin Institute of Technology, Harbin, 150090, China \\ ${ }^{\mathrm{b}}$ International Joint Research Center for Arctic Environment and Ecosystem (IJRC-AEE), Polar Academy, Harbin Institute of Technology, Harbin, 150090, \\ China \\ ${ }^{\mathrm{c}}$ IJRC-PTS-NA, Toronto, Ontario, M2N 6X9, Canada \\ d Nanjing Institute of Environmental Sciences, Ministry of Ecology and Environmental, Nanjing, 210042, China \\ e Department of Marine Sciences, Marine College, Shandong University, Weihai, 264209, China \\ ${ }^{\mathrm{f}}$ Yantai Institute of Coastal Zone Research, Chinese Academy of Sciences, Yantai, China \\ ${ }^{\mathrm{g}}$ Institute of Natural Sciences, North-Eastern Federal University, Russia \\ h Institute of Ocean Sciences, Department of Fisheries and Oceans, P.O. Box 6000, Sidney, BC, V8L 4B2, Canada
}

\section{H I G H L I G H T S}

- Rationality of equilibrium between air and aerosols in Level-III model is examined.

- A level-III model without equilibrium assumption is developed.

- Steady state and not equilibrium between air and aerosols is confirmed by the model.

- Equilibrium between air and aerosols leads a false steady state solution in a system.

- Steady state between air and aerosols should be used in Level-III model.

\section{A R T I C L E I N F O}

\section{Article history:}

Received 24 October 2020

Received in revised form

3 January 2021

Accepted 4 January 2021

Available online 8 January 2021

Handling Editor: Dr. R Ebinghaus

\section{Keywords:}

Fugacity model

Equilibrium

\section{G R A P H I C A L A B S T R A C T}

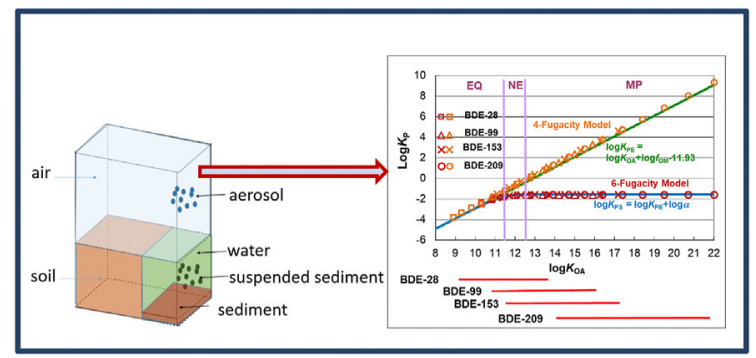

\begin{abstract}
A B S T R A C T
In this paper, two level III fugacity models are developed and applied using an environmental system containing six compartments, including air, aerosols, soil, water, suspended particulate matters (SPMs), and sediments, as a "unit world". The first model, assumes equilibrium between air and aerosols and between water and SPMs. These assumptions lead to a four-fugacity model. The second model removes these two assumptions leading to a six-fugacity model. The two models, compared using four PBDE congeners, BDE-28, $-99,-153$, and -209 , with a steady flux of gaseous congeners entering the air, lead to the following conclusions. 1 . When the octanol-air partition coefficient $\left(K_{\mathrm{OA}}\right)$ is less than $10^{11.4}$, the two models produce similar results; when $K_{\mathrm{OA}}>10^{11.4}$, and especially when $K_{\mathrm{OA}}>10^{12.5}$, the model results diverge significantly. 2. Chemicals are in an imposed equilibrium in the four-fugacity model, but in a steady state and not necessary an equilibrium in the six-fugacity model, between air and aerosols. 3 . The results from the six-fugacity model indicate an internally consistent system with chemicals in steady
\end{abstract}

\footnotetext{
* Corresponding author. International Joint Research Center for Arctic Environment and Ecosystem (IJRC-AEE), Polar Academy, Harbin Institute of Technology, Harbin, 150090, China.

E-mail address: dr_li_yifan@163.com (Y.-F. Li).
} 
Steady state

Particle/gas partition

SVOCs state in all six compartments, whereas the four-fugacity model presents an internally inconsistent system where chemicals are in equilibrium but not a steady state between air and aerosols. 4 . Chemicals are mass balanced in air and aerosols predicted by the six-fugacity model but not by the four-fugacity model. If the mass balance in air and aerosols is achieved in the four-fugacity model, the condition of equilibrium between air and aerosols will be no longer valid.

() 2021 Elsevier Ltd. All rights reserved.

\section{Introduction}

Multimedia environmental fate models are capable of using well-known physicochemical properties together with information on spatial and temporal emissions and climate information to provide a comprehensive picture of the environmental behavior of organic chemicals as they transport away from sources (Mackay and Paterson, 1981, 1991; Dale et al., 2015a, 2015b; Di Guardo et al., 2018). Such models are used to identify the important transport pathways of chemicals in multiple media, provide approximate predictions of concentrations in environmental compartments, and determine the final fate (Mackay and Paterson, 1991; Wania and Mackay, 1995; Zhang et al., 2015). Given the difficulty of monitoring multiple media in the global environment, these multimedia fate models provide powerful tools for governments to make rational decisions on chemical emission control. In addition, the evaluation model constructed by multimedia fugacity method could accurately simulate migration process of pollutants from sources to organisms and exposure level for human body (Arnot and Mackay, 2008; Li et al., 2018).

Fugacity models can be run under steady- and unsteady-state conditions, and can be categorized as level I, II, III, or IV reflecting an increasing complexity in the mass balance equations (Mackay, 2001). The level III fugacity models have been more widely used as they are more realistic than levels I and II models and simpler than level IV models. For example, Globo-POP (Wania and Mackay, 1993, 1995), ChemRange (Scheringer, 1996), Equilibrium Criterion (EQC) (Mackay et al., 1996), Transport and Persistence Level III (TaPL3) (Mackay and Paterson, 1991; Beyer et al., 2000), and the multimedia urban model (MUM) (Diamond et al., 2001) may all be considered as level III models (Table S1, Supporting Information (SI)).

Currently used Level III fugacity models consider the entire system as a steady state. However, within that steady state, chemicals are assumed to be in equilibrium between gaseous and particulate phases in the bulk air compartment, and between liquid and suspended particulate matters (SPMs) in the bulk water compartment. This treatment in the models raises two questions. (1) What are real states for chemicals partitioning between gaseous and particulate phases in the atmosphere and between liquid and SPMs in aquatic systems? (2) If steady state between gas and particles or between liquid and SPMs differs from equilibrium, then can level III model results be considered a true representation of steady state for the entire system? Answering these two questions is crucial to determining whether or not the currently used level III models actually reflect the true conditions of a steady state system.

Actually, our research indicated that SVOCs are in the steady state, not equilibrium, between gas and particles in the atmosphere, and equilibrium is only an approximation when the particle deposition can be ignored (Li et al., 2015). The SVOCs in the atmosphere reach steady non-equilibrium state before reaching equilibrium between gas- and particle-phases (Li et al., 2020). Equilibrium between particles and gas is an ideal thermodynamic state that is not achieved in a real world where particle deposition cannot be neglected. Another explanation involves the particle's residence time (Mackay et al., 2019). Similarly, there are studies have also shown that the particle- and gas-phase partitioning of SVOCs in indoor air cannot achieve equilibrium (Weschler and Nazaroff, 2010; Parnis et al., 2020).

The objective of the present study is to tackle the above two questions. To do this, we assume a six-compartment system containing gas and particle in bulk air, liquid and suspended particulate matters (SPMs) in bulk water, soil, and sediments as a "unit world" suggested by Mackay (2001). Using this basis, we develop one level III model to study the steady state of a chemical in this system assuming equilibrium between gas and particle and between liquid and SPMs and a second model that removes these two equilibrium conditions. We then compare the results of these two models in terms of intermedia transport and projected fluxes between gas and particles and between liquid and SPMs for the selected chemicals, and finally the two questions are answered based on the results of the two models.

\section{Methods}

\subsection{Six-compartment system}

Evaluative environmental four- and eight-compartment systems were introduced as "unit worlds" by Mackay (2001) to illustrate the application of the general principles of environmental partitioning. In the present study, we use a six-compartment system as the "unit world", which comprises gas, particles, liquid, SPMs, soil, and sediments, as indicated in Fig. 1. The partitioning of SVOCs between particles and gas is termed particle- and gas-phases $(\mathrm{P} / \mathrm{G})$ partitioning; in the water compartment, the partitioning of SVOCs between SPMs and liquid is called solid- and dissolvedphase (S/D) partitioning. Environment parameters of the sixcompartment systems can be found in Table S2, and the subscripts for these six compartments used in this study are listed in Table S3. In the present paper, greater attention is paid to S/D partitioning in water, and $P / G$ partitioning in the atmosphere in particular.

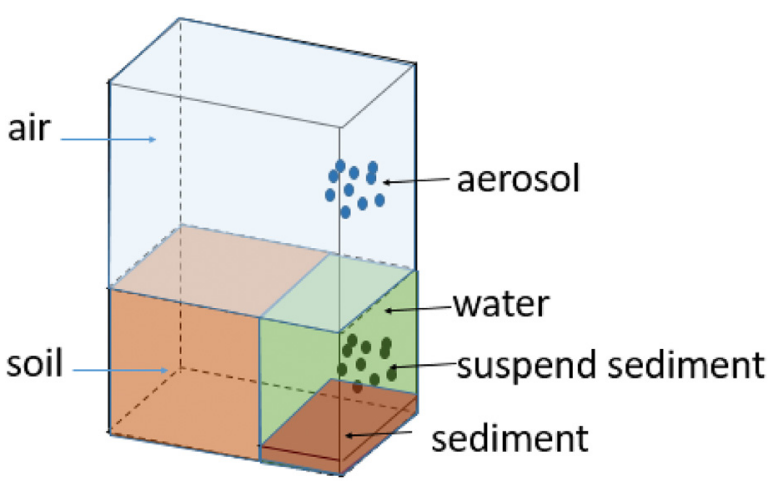

Fig. 1. Evaluative six-compartment environment. 


\subsection{Physicochemical properties}

The physicochemical properties for selected PBDE congeners are listed in Tables S4, S5a and S5b. The octanol-air partition coefficient $\left(K_{\mathrm{OA}}\right)$, the dimensionless Henry's law constant, $K_{\mathrm{AW}}$, and the octanol-water partition coefficient $\left(K_{\mathrm{OW}}\right)$ are chosen from different sources, and fairly subject to thermodynamics constraints. These parameters are all functions of temperature, following a ClausiusClapeyron relationship with the Clausius-Clapeyron coefficients given in Tables S4, S5a and S5b.

\subsection{Particle/Gas partitioning}

The $\mathrm{P} / \mathrm{G}$ partitioning quotient of SVOCs, $K_{\mathrm{P}}$, is commonly defined as (Yamasaki et al., 1982; Pankow and Bidleman, 1991; Li et al., 2015)

$K_{P}=C_{P A} / T S P / C_{G}$

where $C_{\mathrm{G}}\left(\mathrm{pg} \mathrm{m}^{-3}\right.$ air) and $C_{\mathrm{PA}}\left(\mathrm{pg} \mathrm{m}^{-3}\right.$ air) are the concentrations of SVOCs in atmospheric gas and particle phases, respectively, and TSP ( $\mu \mathrm{g} \mathrm{m}^{-3}$ air) is the concentration of total suspended particles in air. At equilibrium, $K_{\mathrm{P}}$ becomes the partition coefficient $\left(K_{\mathrm{PE}}\right)$ and at steady state, $K_{\mathrm{P}}$ becomes the partition quotient at steady state ( $\left.K_{\mathrm{PS}}\right)$.

\subsection{Solid/Dissolved partitioning}

Solid/Dissolved (S/D) partitioning behavior of SVOCs in water has been investigated by many research groups. Here, we define the $S / D$ partition quotient of a chemical in water as

$K_{S D}=C_{S} / S P M / C_{D}$

where $C_{\mathrm{S}}$ is concentration of chemical in solid (SPMs) phase $\left(\mathrm{g} \mathrm{m}^{-3}\right.$ water), $C_{\mathrm{D}}$ is concentration of chemical in dissolved (liquid) phase ( $\mathrm{g} \mathrm{m}^{-3}$ water), and SPM is the concentration of suspended particle matter $\left(\mathrm{g} \mathrm{m}^{-3}\right)$.

\section{5. $P / G$ partitioning quotient under steady state}

To consider also the wet and dry deposition of particles, Li and co-workers developed a steady-state $\mathrm{P} / \mathrm{G}$ partitioning equation (referred to here as the Li-Ma-Yang equation) (Li et al., 2015):

$\log K_{P S}=\log K_{P E}+\log \alpha$

where $K_{\mathrm{PS}}$ is the partition quotient in steady state, $\log K_{\mathrm{PE}}$ is designated as the equilibrium term, given by (Harner and Bidleman, 1998)

$\log K_{P E}=\log K_{O A}+\log f_{O M}-11.91$

and $\log \alpha$ is the non-equilibrium term given by

$\log \alpha=-\log \left(1+4.18 \times 10^{-11} f_{O M} K_{O A}\right)$

which is a function of $f_{\mathrm{OM}}$ and $K_{\mathrm{OA}}$. This steady-state equation can be applied for various SVOCs including PBDEs (Li et al., 2015, 2017; Besis et al., 2017; Wang et al., 2017; Cao et al., 2018), PCBs (Wang et al., 2017), organochlorine pesticides (OCPs) (Qiao et al., 2019), PCDD/Fs (Cao et al., 2018), several alternative halogenated flame retardants ( $\mathrm{Li}$ et al., 2016a), non-PBDE brominated flame retardants (Li et al., 2016b), and short- and medium-chain chlorinated paraffins (Jiang et al., 2020).

The most striking results from steady-state Eq. (3) are (Fig. S1a,
(1) Equilibrium is a special case of steady state when $\log \alpha=0$, or when the wet and dry deposition of particles can be ignored.

(2) Two thresholds of $\log K_{\mathrm{OA}}\left(\log K_{\mathrm{OA} 1}=11.4, \log K_{\mathrm{OA} 2}=12.5\right)$ are important physicochemical boundaries that divide the partitioning behavior of SVOCs into three domains (Fig. S1a): equilibrium (EQ) when $\log K_{\mathrm{OA}} \leq \log K_{\mathrm{OA} 1}$, non-equilibrium (NE) when $\log K_{\mathrm{OA} 1}<\log K_{\mathrm{OA}}<\log K_{\mathrm{OA} 2}$, and maximum partition (MP) when $\log K_{\mathrm{OA}} \geq \log K_{\mathrm{OA} 2}$. The two corresponding time thresholds, $t_{\mathrm{TH} 1}$ and $t_{\mathrm{TH} 2}$, are shown in Fig. S1b.

(3) In the MP domain, the values of $\log K_{\mathrm{PS}}$ are a constant (-1.53) (Fig. S1a).

In this paper, we rely mostly on the three domains, EQ NE, and, especially, MP, to characterize and compare the behavior of selected PBDE congeners in the six compartments with special emphasis on the two compartments, air and aerosols, in the atmosphere.

\subsection{Four-fugacity model}

The common approach to $\mathrm{P} / \mathrm{G}$ and S/D partitioning of SVOCs in Level-III models is to assume chemical equilibrium between the particulate and gaseous phases in the atmosphere and between solid- and dissolved-phases in water. This assumption means that chemical fugacity has to be identical in gas- and particle-phases in the atmosphere $\left(f_{1}\right)$, and in solid- and dissolved-phases in the water $\left(f_{2}\right)$ (Fig. 2). Thus, in this six-compartment system, there are six phases (gaseous and particulate in air, water dissolved and solid phases in water, sediment, and soil) but only four fugacities, $f_{1}$ (air, including gas- and particle-phases), $f_{2}$ (water, including dissolved and solid-phases), $f_{4}$ (sediment), and $f_{3}$ (soil). The model to be developed in this study is referred to as "six-compartment, fourfugacity" model or, more simply four-fugacity model.

The arrows in Fig. 2 depict the intermedia processes. Advection of air or water is not considered here for simplicity. Subscripts 1, 2, 3 and 4 are used to designate air, water, soil, and sediment, respectively. Flux is calculated as the product of the transport parameters $D$ value and fugacity $f$, where the intermedia D is listed in Table S6a, with the partition parameter $K$ and fugacity capacity $\mathrm{Z}$ given in Table S6c and Table S6d, respectively. There are seven intermedia D values $\left(D_{12}, D_{21}, D_{13}, D_{31}, D_{32}, D_{24}\right.$, and $\left.D_{42}\right)$ and, accordingly, seven intermedia fluxes $\left(F_{12}, F_{21}, F_{13}, F_{31}, F_{32}, F_{24}\right.$, and $\left.F_{42}\right)$. Four linear equations describing the four-fugacity system are as follows:

$E_{i}+\sum D_{j i} f_{i}=\sum D_{j k} f_{i}+D_{T i} f_{i}(i=1,2,3,4)$

where $E_{i}$ is the emission rate $\left(\mathrm{mol} \mathrm{h}^{-1}\right)$ of a chemical entering compartment $i, D_{j i}$ is the $D$ value $\left(\mathrm{mol} \mathrm{Pa}^{-1} \mathrm{~h}^{-1}\right)$ from compartment $j$

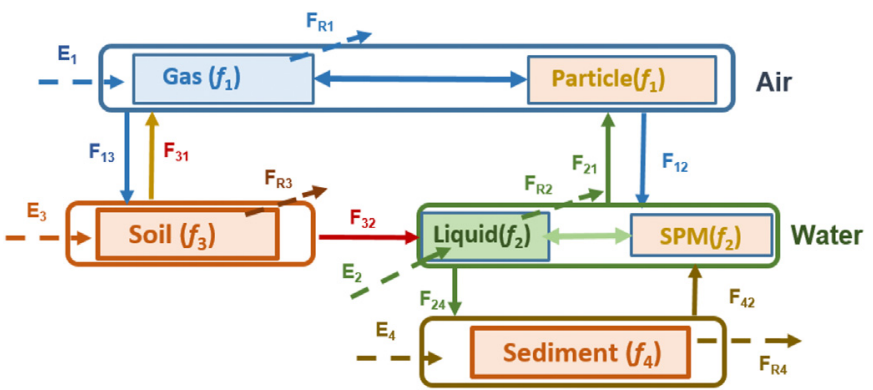

Fig. 2. Six-compartment and four-fugacity system. $E_{\mathrm{i}}$ is emission rate $\left(\mathrm{mol} \mathrm{h}^{-1}\right)$ to compartment $\mathrm{i}, F_{\mathrm{ij}}$ is intermedia flux from compartment $\mathrm{i}$ to compartment $\mathrm{j}\left(\mathrm{mol} \mathrm{h}^{-1}\right)$, $F_{\mathrm{Ri}}$ is flux by reaction $\left(\mathrm{mol} \mathrm{h}^{-1}\right)$, and $f_{\mathrm{i}}$ is fugacity of chemical in compartment $\mathrm{i}(\mathrm{Pa})$. Air, water, soil, and sediment are subscripted $1,2,3$, and 4 respectively. Advection of the system is not considered here. 
to compartment $i, D_{\mathrm{ik}}$ is the $D$ value ( $\mathrm{mol} \mathrm{Pa} \mathrm{Pa}^{-1}$ ) from compartment $i$ to compartment $k, D_{\mathrm{Ri}}$ is the reaction rate $D$ value (mol $\mathrm{Pa}^{-1} \mathrm{~h}^{-1}$ ) in compartment $i$, and $f_{i}$ is the fugacity of the chemical in compartment $i$ (Pa) (see Fig. 2). If air, water, soil, and sediment are subscripted $1,2,3$, and 4 respectively (Table S3), and only one emission to air $\left(E_{1}\right)$ is considered, then we can write the above equation as a group of four linear equations as follows:Air (1, including gas- and particle-phases having the same fugacity)

$E_{1}+D_{21} f_{2}+D_{31} f_{3}=\left(D_{12}+D_{13}+D_{R 1}\right) f_{1}=D_{T 1} f_{1}$

Water (2, including dissolved and solid phases with the same fugacity)

$D_{12} f_{1}+D_{32} f_{3}+D_{42} f_{4}=\left(D_{21}+D_{24}+D_{R 2}\right) f_{2}=D_{T 2} f_{2}$

Soil (3)

$D_{13} f_{1}=\left(D_{31}+D_{32}+D_{R 3}\right) f_{3}=D_{T 3} f_{3}$

Sediment (4)

$D_{24} f_{2}=\left(D_{42}+D_{R 4}\right) f_{4}=D_{T 4} f_{4}$

$D_{\mathrm{Ti}}$ is the sum of all loss $D$ values from medium $i$ (Table S6a).

\subsection{Six-fugacity model}

In our opinion, the prevalent treatment of $P / G$ chemical exchange in the atmosphere in level III models described above is not strictly correct. The level III model assumes a non-equilibrium distribution and produces steady-state solutions using linear Eqs. (7a)-(7d), which implies that chemicals are in a steady-state between compartments (air-water, air-soil, soil-water, and watersediment) and do not necessarily have to be at equilibrium. Contradicting this, the chemical states within the atmosphere and hydrosphere compartments have an imposed equilibrium between the particulate and gaseous in air or solid and dissolved phases in water. Obviously, both states cannot necessarily co-exist at the same time. Most importantly, our research already indicated that SVOCs are in a steady state, not equilibrium, between air and aerosols in the atmosphere (Li et al., 2015, 2017, 2020).

To overcome this objection, we propose removing the assumption of chemical equilibrium between phases within the atmospheric and hydrospheric compartments. In other words, all six compartments in the system (gas and particle in atmosphere, liquid and SPMs in water, sediment, and soil) are provided with their own fugacity, with the particles fugacity now designated $f_{5}$

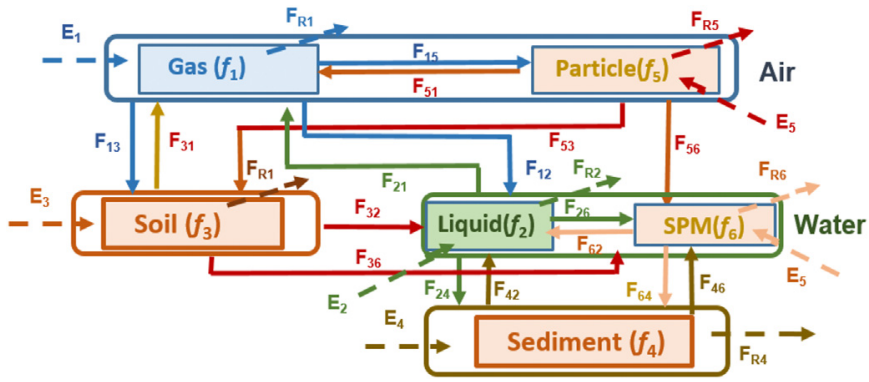

Fig. 3. Six-compartment and six-fugacity system. $E_{\mathrm{i}}$ is the emission rate $\left(\mathrm{mol} \mathrm{h}^{-1}\right)$ to compartment $\mathrm{i}, F_{\mathrm{ij}}$ is the flux from phase $\mathrm{i}$ to phase $\mathrm{j}\left(\mathrm{mol} \mathrm{h}^{-1}\right), F_{\mathrm{Ri}}$ is the flux by reaction $\left(\mathrm{mol} \mathrm{h}^{-1}\right)$, and $f_{\mathrm{i}}$ is the fugacity of chemical in phase $\mathrm{i}(\mathrm{Pa})$. Gas, liquid water, soil, sediment, aerosol, and suspended particle mater are subscripted 1, 2, 3, 4, 5, and 6 respectively. There are 16 intermedia fluxes, including $F_{12}, F_{21}, F_{13}, F_{31}, F_{32}, F_{24}, F_{42}, F_{15}$, $F_{51}, F_{53}, F_{56}, F_{62}, F_{26}, F_{36}, F_{46}$, and $F_{64}$ and the SPMs $f_{6}$ (Fig. 3, Table S3). This model becomes, therefore, a "six-compartment, six-fugacity" model, referred to simply as the six-fugacity model.

The six-fugacity model now requires six linear equations instead of four, and 16 intermedia D values $\left(D_{12}, D_{21}, D_{13}, D_{31}, D_{32}, D_{24}, D_{42}\right.$, $\mathrm{D}_{15}, \mathrm{D}_{51}, \mathrm{D}_{53}, \mathrm{D}_{56}, \mathrm{D}_{62}, \mathrm{D}_{26}, \mathrm{D}_{36}, \mathrm{D}_{46}$, and $\mathrm{D}_{64}$ ) (Tables S6b, S6c and S6d), with linear equations following the general form:

$E_{i}+\sum D_{j i} f_{i}=\sum D_{j k} f_{i}+D_{R i} f_{i}=D_{T i} f_{i}(i=1,2,3,4,5,6)$

If only one emission to air $\left(E_{1}\right)$ is considered, then we can write the above equation as a group of six linear equations as follows: (Harner and Bidleman, 1998; Mackay et al., 2019) Air: Gas-phase (1):

$E_{1}+D_{21} f_{2}+D_{31} f_{3}+D_{51} f_{5}=\left(D_{12}+D_{13}+D_{15}+D_{R 1}\right) f_{1}=D_{T 1} f_{1}$

Air: Particle-phase (5):

$D_{15} f_{1}=\left(D_{51}+D_{53}+D_{56}+D_{R 5}\right) f_{5}=D_{T 5} f_{5}$

Water: Dissolved-phase (2):

$D_{12} f_{1}+D_{32} f_{3}+D_{42} f_{4}+D_{62} f_{6}=\left(D_{21}+D_{24}+D_{26}+D_{R 2}\right) f_{2}=D_{T 2} f_{2}$

Water: Solid-phase (6):

$D_{26} f_{2}+D_{36} f_{3}+D_{46} f_{4}+D_{56} f_{5}=\left(D_{62}+D_{64}+D_{R 6}\right) f_{6}=D_{T 6} f_{6}$

Soil phase (3):

$D_{13} f_{1}+D_{53} f_{5}=\left(D_{31}+D_{32}+D_{36}+D_{R 3}\right) f_{3}=D_{T 3} f_{3}$

Sediment phase (4):

$D_{24} f_{2}+D_{64} f_{6}=\left(D_{42}+D_{46}+D_{R 4}\right) f_{4}=D_{T 4} f_{4}$

$D$ values for intermedia process between air and aerosols ( $\mathrm{Li}$ et al., 2015), $D_{15}$ and $D_{15}$, are given by

$D_{15}=D_{51}=A_{p} k_{P G} Z_{G}$

where $A_{\mathrm{P}}\left(\mathrm{m}^{2}\right)$ is surface area of the particles, $Z_{\mathrm{G}}$ is the $\mathrm{Z}$ value for gas, and $k_{\mathrm{PG}}\left(\mathrm{m} \mathrm{h}^{-1}\right)$ is over all mass transfer coefficient between gas and particles (Table S6e). Detailed information can be found in SI, Text S1.

The $\mathrm{D}$ value for the partitioning processes between liquid and SPMs is given by

$D_{26}=D_{62}=A_{S} k_{S D} Z_{D}$

where $A_{S}\left(\mathrm{~m}^{2}\right)$ is surface area of the SPMs, $Z_{D}$ is the $Z$ value for liquid, and $k_{\mathrm{SD}}\left(\mathrm{m} \mathrm{h}^{-1}\right)$ is the S/D partitioning mass transfer coefficient given in SI, Text S2 and Table S6e.

\subsection{Emissions and monitoring data PBDEs in Harbin}

To evaluate how well the two models reflect real environmental data, we chose the City of Harbin, a northeastern city of China, as the modeling area. The parameters of environmental compartment for Harbin are provided in Table S7. We calculate the PBDE emission in the city as input to the model, the results of which in air and soil for seven selected PBDE congeners (BDE-28, 
$-47,-99,-100,-153,-154$, and -209$)$ are compared with the monitoring data measured in the city. PBDE emissions in Harbin estimated for 2008 in Table S8, and monthly emissions are presented in Table S9. The total emission rate for all PBDE congeners was $3.46 \times 10^{2} \mathrm{~kg} \mathrm{y}^{-1}$ or $3.94 \times 10^{-2} \mathrm{~kg} \mathrm{~h}^{-1}$, and the highest monthly emissions were $1.03 \times 10^{2} \mathrm{~kg}$ for October, November, and December. Emission of seven individual target PBDE congeners in Harbin are listed in Table S10. Detailed information can be found in SI, Text S3.

\section{Results}

In this section, we present the results from the four-fugacity and six-fugacity models in a six-compartment "unit world", and compare them. For this comparison, we have chosen a range in ambient temperature of $-40^{\circ}$ to $40^{\circ} \mathrm{C}$ with intervals of $10^{\circ} \mathrm{C}$, and limit ourselves to four PBDE congeners, BDE-28, -99, -153, and -209 , because these compounds provide a wide range of log$K_{\mathrm{OA}}$ values, from $8.9\left(\mathrm{BDE}-28\right.$ at $40{ }^{\circ} \mathrm{C}$ ) to $22.0\left(\mathrm{BDE}-209\right.$ at $-40{ }^{\circ} \mathrm{C}$ ) over the ambient temperature range (see Fig. S2). A continuous emission of each gaseous PBDE congener $\left(E_{1}=0.01 \mathrm{~mol} \mathrm{~h}^{-1}\right)$ over the whole system is assumed.

\subsection{Fugacity}

The fugacities for BDE-28, $-99,-153$, and -209 as a function of temperature for both models are presented in Fig. S3a, SI, and the ratios of predicted fugacities between six fugacity and four fugacity models as a function of temperature are depicted in Fig. S3b, SI, showing that there are similarities and differences between the results obtained by the two models.

The fugacities given by the models for five of the phases aerosols, water, SPMs, sediment, and soil - are almost identical (Figs. S3a and S3b). These five phases can be divided into two groups: the water body group, including water, SPMs, and sediment compartments, and the non-water body group, containing soil and aerosol compartments. The fugacities of non-water body group for all four congeners decrease monotonically with decreasing temperature, whereas the fugacity curves for the water body group decrease with decreasing temperature and then become constant when temperature becomes $\leq 0$. It is interesting to note that, in the water body group, the two models predict the same fugacities for dissolved- and solid-phases for all four PBDE congeners, which implies that the PBDE congeners in water are in steady-state and equilibrium or close to equilibrium as well.

The big difference between the predictions of the two models is for the fugacities of the gas-phase for all four PBDE congeners (Fig. 3a and b, and 4). In the four-fugacity model the fugacity of the gaseous PBDE is assumed to be equal to the fugacity in the particulate phase, decreasing monotonically with decreasing temperature. In contrast, the six-fugacity model produces a gaseous PBDE fugacity distinctly different from the fugacity of the particulate phase, but similar to the water body group, first decreasing as temperature decreases, and then approaching a constant after the temperature reaches the second threshold temperature $\left(t_{\mathrm{TH} 2}\right)$ $\left(-9.2^{\circ} \mathrm{C}, 19.7{ }^{\circ} \mathrm{C}\right.$, and $34.8{ }^{\circ} \mathrm{C}$ for BDE-28, -99 , and -153 , respectively) (Fig. S1b), and the system enters the MP Domain. For BDE209, which is within the MP Domain for the entire temperature range, the gaseous phase fugacity is almost constant and invariable with temperature (Fig. 4).

\subsection{Concentrations and mass fractions}

Similar to the fugacity results, the concentrations of the four selected PBDE congeners predicted by the two models also have

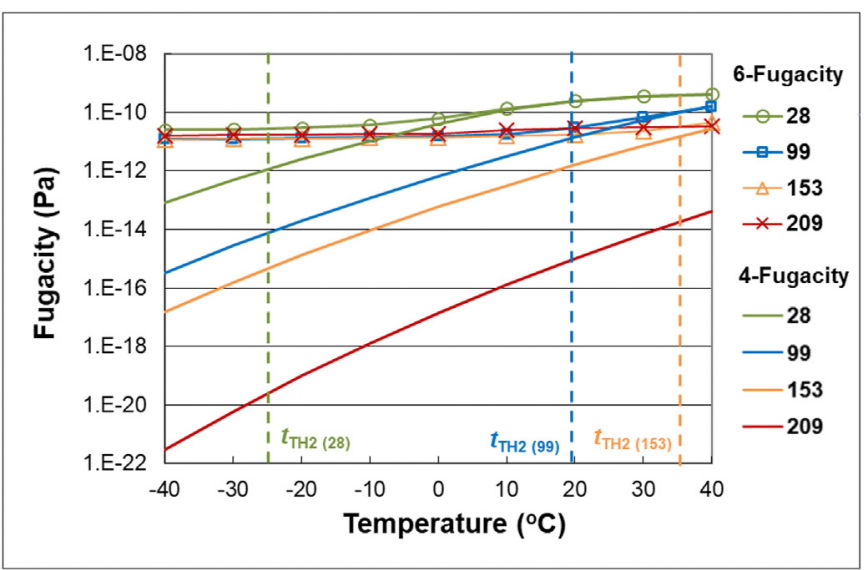

Fig. 4. Fugacity $(\mathrm{Pa})$ in gaseous phase for four selected PBDE congeners (BDE-28, $-99,-153$, and -209 ) as functions of temperature obtained by four- and six-fugacity models. The vertical dashed lined are for the second temperature threshold values. (Fig4-5b_4PBDE_Study).

similarities and differences, as depicted in Fig. S4. Concentrations of the four selected BDE congeners in all five phases (except the gasphase) predicted by these two models are almost identical, increasing monotonically with decreasing temperature in the EQ Domain, and reaching constants in the MP Domain (Fig. S4). As showing in Fig. 4a, the six phases can be divided into three groups based on PBDE concentrations. The first group, sediment and soil, are highest among the six phases, and therefore contain the largest reservoirs for PBDEs. The second group, liquid and SPMs phases in the water exhibit mid-range concentrations and the third group, the gas- and aerosols in the atmosphere, have the lowest concentrations.

The differences are obvious. As shown in Fig. 5 and S4, the fourfugacity model projects that gaseous concentrations of PDBEs decrease quickly and monotonically with temperature for the entire temperature range, including the NE and MP Domains. In contrast, the six-fugacity model predicts that the concentrations of the four BDE congeners in the gaseous phase decrease monotonically with decreasing temperature in the EQ Domain, and reach constants in the MP Domain, similar to the behavior in the other five compartments. In general, the concentrations for gaseous PBDEs predicted by the six-fugacity model are much higher than those by the four-fugacity model, and the differences become larger as the number of $\mathrm{Br}$ substitutions increases and the temperature drops. For example, at $20{ }^{\circ} \mathrm{C}$, air concentrations predicted by the six-fugacity model for BDE-28, $-99,-153$, and -209 are 41.4, 6.7, 4.5 and $11.3 \mathrm{pg} \mathrm{m}^{-3}$, respectively, compared to $40.6,3.2,0.4$, and $3.9 \times 10^{-4} \mathrm{pg} \mathrm{m}^{-3}$, predicted by the four-fugacity model. At $-20^{\circ} \mathrm{C}$, the contrast is far greater with air concentrations of 5.6, 3.5, 3.9 and $7.9 \mathrm{pg} \mathrm{m}^{-3}$, respectively, predicted by the six-fugacity model, compared to $4.7 \times 10^{-1}, 5.2 \times 10^{-3}, 4.0 \times 10^{-4}$, and $4.4 \times 10^{-8} \mathrm{pg} \mathrm{m}^{-3}$, predicted by the four-fugacity model. Taking the most extreme example, gaseous BDE-209, concentrations in the gas-phase in the MP Domain predicted by the four-fugacity model are $0.01 \mathrm{pg} \mathrm{m}^{-3}$ when $t=40^{\circ} \mathrm{C}$ to $10^{-10} \mathrm{pg} \mathrm{m}^{-3}$ when $t=-40^{\circ} \mathrm{C}$, which can be treated as zero (Fig. 5). In contrast, the concentrations predicted by the six-fugacity model are from 12.1 to $7.9 \mathrm{pg} \mathrm{m}^{-3}$ over the entire temperature range from $40^{\circ} \mathrm{C}$ to $-40^{\circ} \mathrm{C}$, which cannot be treated as zero and cannot be ignored (Li et al., 2017). Thus, in the MP Domain, PBDE congeners are in a stable steady state with constant concentrations independent of temperature in all six phases in the six-compartment system.

The mass fractions for the four selected PBDE congeners 


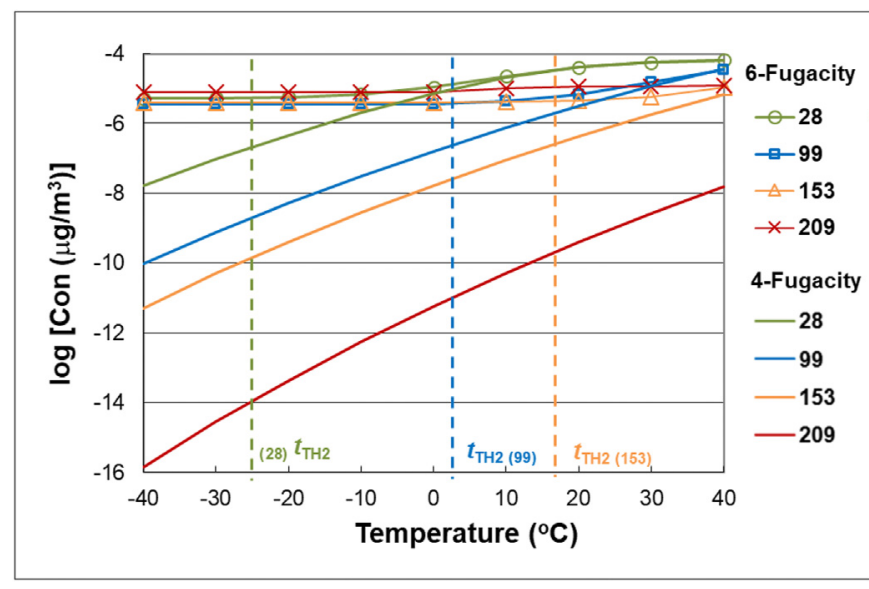

Fig. 5. Concentrations ( $\mu \mathrm{g} \mathrm{m}-3$ ) of four selected PBDE congeners in gas-phase as functions of temperature obtained by four- and six-fugacity models.

predicted by the two models seem identical for all six phases (Fig. S5), but are actually significantly different for four gaseous PBDE congeners by the two models, especially in the MP Domain (Fig. 6). The four-fugacity model predicts zero whereas the sixfugacity model predicts non-negligible amounts $-0.48 \%$ for BDE$28,0.10 \%$ for BDE- $99,0.08 \%$ for BDE- 153 , and $0.05 \%-0.08 \%$ for BDE-209.

\section{3. $P / G$ partitioning behavior in the atmosphere}

The big differences between the six-fugacity and four-fugacity models predictions appear in the atmosphere. What is important here is that, the six-fugacity model provides the opportunity to calculate the $\mathrm{P} / \mathrm{G}$ partitioning quotients of chemicals between gasand particle-phases in the atmosphere under steady state conditions, whereas the four-fugacity model simply imposes particle-gas equilibrium.

The results for the particle/gas partitioning quotients derived from the two models for BDE-28, -99, -153 , and -209 congeners (Fig. 7), indicate that $\log K_{\mathrm{P}}$ values predicted by the four-fugacity model are very close to the straight line for $\log K_{\mathrm{PE}}$ (Eq. (4)). This is not surprising given that this equilibrium condition is imposed in the four-fugacity model. In contrast, the $\log K_{\mathrm{P}}$ values predicted by the six-fugacity model are very close to the curve for log $K_{\mathrm{PS}}$ (Eq. (3)), the steady-state partition quotients (Li et al., 2015), as shown in Fig. S1a. A striking conclusion is that, for this six-compartment system, the values for $\log K_{\mathrm{P}}$ in air for these selected PBDE congeners or, indeed, many other PBDE congeners, reach a constant value of -1.60 in the MP Domain, which is very close to -1.53 , the constant value that $\log K_{\mathrm{P}}$ attains when $\log K_{\mathrm{OA}}$ reaches the MP Domain (Li et al., 2015). This suggests that the steady-state theory derived by considering only atmospheric processes and observations ( $\mathrm{Li}$ et al., 2015) is confirmed by the six-fugacity model, which incorporates four other environmental compartments (water, SPM, soil, sediment).

\subsection{Solid/Dissolved (S/D) partitioning behavior in water}

Fig. S6 shows the predicted results of the two models for the solid/dissolved (S/D) partitioning coefficient, $\log K_{\mathrm{PW}}$, for the four target PBDEs congeners as function of temperature. The S/D partitioning of the target congeners does not change within the ambient temperature range, and $K_{\mathrm{PW}}$ is constant. The four- and six-fugacity models both produce the same results, indicating that S/D partitioning behavior of PBDEs in water can be considered to be in steady state and equilibrium, and not affected by temperature.

\subsection{Fluxes}

The net flux of a chemical between two compartments becomes zero when equilibrium is established between these two compartments, whereas the input and output fluxes of a chemical in a compartment become equal when the chemical is in mass balance and in steady state for the compartment.

We use BDE-99 as an example to discuss the model-predicted fluxes of PBDEs among the six compartments because this chemical has an informative distribution pattern in the three domains between $-40{ }^{\circ} \mathrm{C}$ and $40{ }^{\circ} \mathrm{C}$ (see Figs. S2 and S3a).

\subsubsection{General description}

Fig. 8 depicts fluxes $\left(\mathrm{mol} \mathrm{h}^{-1}\right)$ for BDE-99 for six phases at $40{ }^{\circ} \mathrm{C}$ and $-40{ }^{\circ} \mathrm{C}$ predicted by the two models (fluxes for other temperatures are given in Fig. S7, SI). When the temperature is $40^{\circ} \mathrm{C}$, BDE-99 is in the EQ Domain, and fluxes predicted by the two models are close. When temperature is $-40^{\circ} \mathrm{C}$, BDE-99 is in the MP Domain and fluxes predicted by the two models are almost the same between any two compartments with three exceptions related to the air compartment, which are from air to aerosols (F15), air to water (F12), and air to soil (F13). The fluxes predicted by the six-fugacity model are much higher ( $>4$ orders of magnitudes) than those projected by the four-fugacity model in terms of these three fluxes.

Fig. 9 depicts the input fluxes of BDE-99 in the six-compartment system as functions of temperature predicted by the two models. The input fluxes of BDE-99 for the air, soil, water, SPM, and sediment compartments are almost identical, but those for aerosols are very different. While the input fluxes of BDE-99 for aerosols predicted by six-fugacity model are almost the same as those for air, decreasing slowly and reaching a constant in the MP Domain, the input fluxes for aerosols predicted by four-fugacity model are much smaller from those for air, decreasing monotonously, from $4.84 \times 10^{-2}$ at $40^{\circ} \mathrm{C}$ to $1.25 \times 10^{-7} \mathrm{~mol} \mathrm{~h}^{-1}$ at $-40^{\circ} \mathrm{C}$.

\subsubsection{Air and aerosol fluxes}

The big differences in fluxes predicted by the two models appear for the air and aerosols in the atmosphere as discussed below.

Fig. 10 presents both inputs and outputs for individual air and aerosols as functions of temperature: in the six-fugacity model, the input and output fluxes of BDE-99 for individual air and aerosols are identical, as for the remaining four compartments, indicating a mass balance of BDE-99 throughout the whole system. This chemical does not have any net fluxes to or from any compartments in the system and is, therefore, in "steady state". However, the input and output fluxes of BDE-99 predicted by the four-fugacity model differ for individual air and aerosols, indicating non-zero net fluxes, meaning not mass balanced or not in steady state for these two compartments.

BDE-99 transfer between air and aerosols predicted by the two models are also very different. As depicted by Fig. 8 and S7, the BDE99 exchange fluxes predicted by the four-fugacity model are always identical between air and aerosols at any temperature, indicating a zero net flux or equilibrium of BDE-99 between these two compartments. In contrast, the six-fugacity model projects a difference in the BDE-99 exchange fluxes between air and aerosols. For example, as indicated in Fig. 8, when the temperature is $40^{\circ} \mathrm{C}$, BDE99 is in the EQ Domain. The fluxes in both directions between air and aerosols predicted by the four-fugacity model are the same, $0.048 \mathrm{~mol} \mathrm{~h}^{-1}$, whereas the fluxes between air and aerosols predicted by the six-fugacity model are not identical, but the difference 

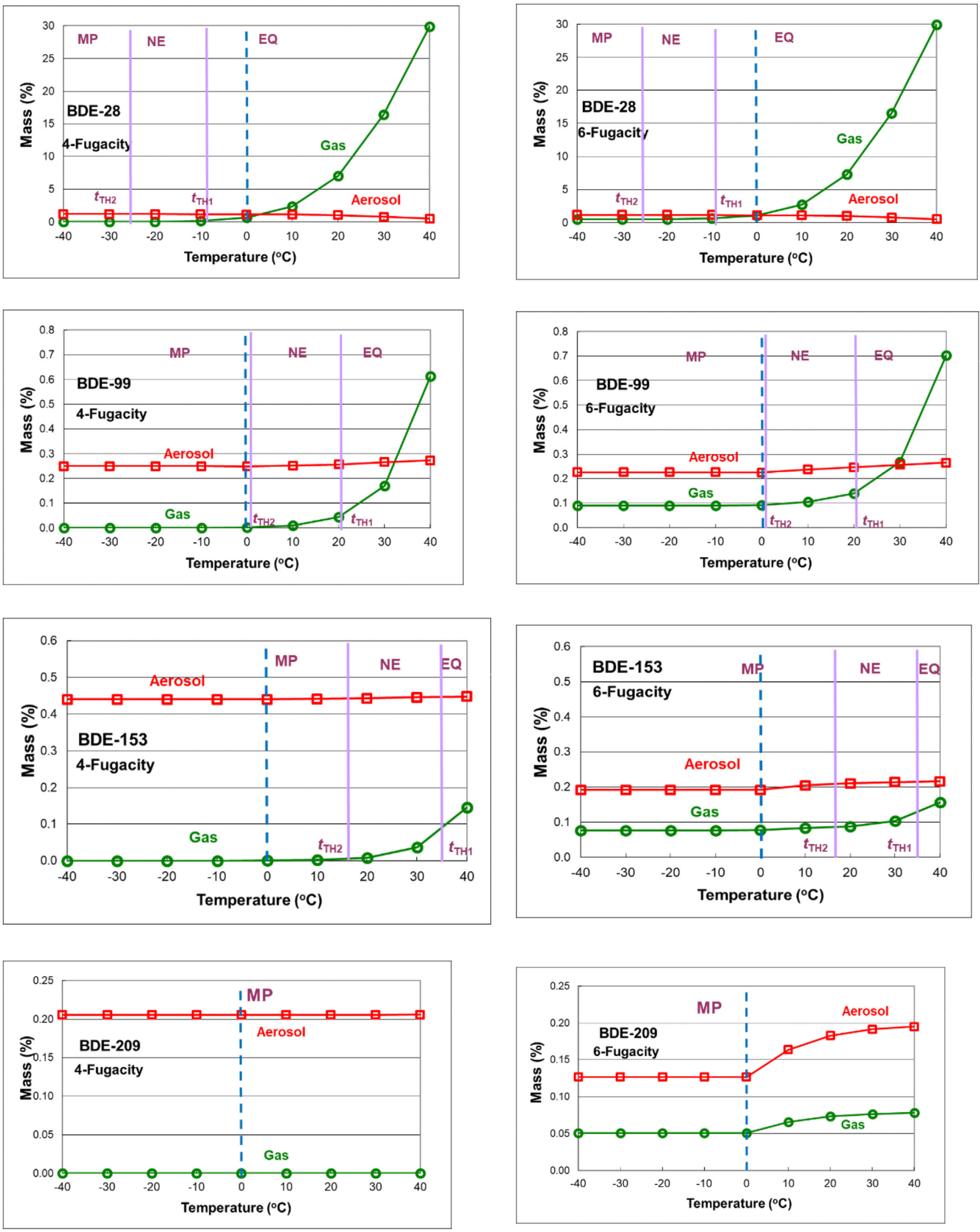

Fig. 6. Mass fractions (\%) in gas-phase and aerosol-phase as functions of temperature for four selected PBDE congeners obtained by four- and six-fugacity models. 


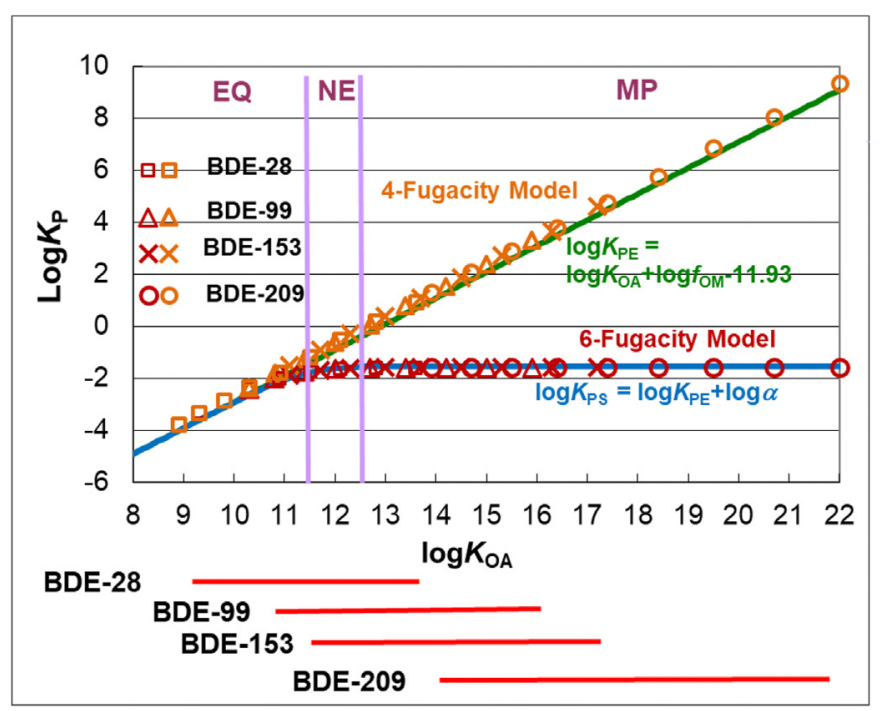

Fig. 7. $\mathrm{P} / \mathrm{G}$ partitioning behavior as functions of $\log K_{\mathrm{OA}}$ for 4 selected $\mathrm{PBDE}$ congeners obtained by four- and six-fugacity models. Marks in orange are obtained by using fourfugacity model, and marks in dark red are obtained by using six-fugacity model. (For interpretation of the references to colour in this figure legend, the reader is referred to the Web version of this article.)

is relatively insignificant $\left(0.061 \mathrm{~mol} \mathrm{~h}^{-1}\right.$ from air to aerosols and $0.052 \mathrm{~mol} \mathrm{~h}^{-1}$ from aerosol to air). Now consider when the temperature of $-40{ }^{\circ} \mathrm{C}$ and BDE-99 is in the MP Domain. The fourfugacity model again projects equal fluxes in both directions $\left(1.25 \times 10^{-7} \mathrm{~mol} \mathrm{~h}^{-1}\right.$, which is almost zero) whereas the sixfugacity model fluxes are very different $\left(0.009 \mathrm{~mol} \mathrm{~h}^{-1}\right.$ from air to aerosol and only $1.12 \times 10^{-7} \mathrm{~mol} \mathrm{~h}^{-1}$ (almost zero) from aerosol to air). In other words, almost no exchange of BDE-99 between air and aerosols is predicted by the four-fugacity model, and almost no transfer of BDE-99 from aerosols to air, but a significant amount of BDE-99 (0.009 $\mathrm{mol} \mathrm{h}^{-1}$, close to the emission to the air) from air to aerosol is predicted by the six-fugacity model.

To illustrate this more clearly, we examined in detail the data for BDE-99 in the atmosphere. Fig. 10 depicts the input and output fluxes of BDE-99 in air and aerosol in the atmosphere at different temperatures predicted by the two models. The right panel, which shows results for the six-fugacity model, indicates several things nicely. 1 . The input and output fluxes of BDE-99 in air are almost equal to those in aerosols in the atmosphere, which implies that the output of BDE-99 from air is the dominant source of the input of BDE-99 in the aerosol. 2. The input and output fluxes decrease with a decrease in temperature, from $\sim 0.06 \mathrm{~mol} \mathrm{~h}^{-1}$ when $\mathrm{t}=40^{\circ} \mathrm{C}$ to $0.01 \mathrm{~mol} \mathrm{~h}^{-1}$ (= emission) when $t$ is in the MP Domain $\left(t \leq t_{\mathrm{TH} 2}=2.48^{\circ} \mathrm{C}\right)$, suggesting that in this domain the main source of BDE-99 in air is emission, and almost all this enitted BDE-99 is sorbed from air to aerosols, from which enters to the surfaces (water and soil).

The results predicted by the four-fugacity model, however, are different. As shown in the left panel in Fig. 10, input and output BDE-99 are not balanced for either air or aerosols in the atmosphere. This is a very strange situation, indicating that the input fluxes of BDE-99 in air approximately equals the output flux in aerosol, from $\sim 6.5 \times 10^{-2}$ at $40{ }^{\circ} \mathrm{C}$ to $\sim 0.01 \mathrm{~mol} \mathrm{~h}^{-1}$ at $-40{ }^{\circ} \mathrm{C}$, whereas the output in air and input in aerosols are also equal but with a much smaller value, from $5.38 \times 10^{-2}$ at $40{ }^{\circ} \mathrm{C}$ to $1.26 \times 10^{-7}$ at $-40{ }^{\circ} \mathrm{C}$. The difference equals approximately the emission in the MP Domain (the red dashed horizontal line in the left panel of Fig. 10). This means that, the emission entering air at a rate of $0.01 \mathrm{~mol} \mathrm{~h}^{-1}$ goes nowhere, and at the same time, an identical amount of BDE-99 in aerosols originates from nowhere.

The data in Tables 1 and 2 explain this enigma more clearly. The results from the six-fugacity model (Table 1 ) indicate that the total input to air is $1.01 \times 10^{-2} \mathrm{~mol} \mathrm{~h}^{-1}$, including the dominant input from emission $\left(1.00 \times 10^{-2} \mathrm{~mol} \mathrm{~h} \mathrm{~h}^{-1}\right)$ and the rest $\left(\sim 0.01 \times 10^{-2} \mathrm{~mol} \mathrm{~h}^{-1}\right)$ from aerosol, water, and soil. The total output from air is also $1.01 \times 10^{-2} \mathrm{~mol} \mathrm{~h}^{-1}$, indicating a mass balance of BDE-99 in air. These outputs include the dominant portion going to the aerosols $\left(9.00 \times 10^{-3} \mathrm{~mol} \mathrm{~h}^{-1}\right)$, and the rest $\left(\sim 1.06 \times 10^{-3} \mathrm{~mol} \mathrm{~h}^{-1}\right)$ going to water and soil, and lost due to degradation. For aerosols, the only input $\left(9.00 \times 10^{-3} \mathrm{~mol} \mathrm{~h}^{-1}\right)$ is from air, which all goes to water, soil, air and loss due to degradation, also mass balanced.

The results from the four-fugacity model (Table 2) are very different. The inputs to air are identical to those predicted by the six-fugacity model $\left(1.01 \times 10^{-2} \mathrm{~mol} \mathrm{~h}^{-1}\right)$, mostly from emission $\left(1.00 \times 10^{-2} \mathrm{~mol} \mathrm{~h}^{-1}\right)$, but almost no output from air $\left(7.85 \times 10^{-6} \mathrm{~mol} \mathrm{~h}^{-1}\right.$ only), the mass is not balanced. The same results occur also for aerosols. With only input from air $\left(7.03 \times 10^{-6} \mathrm{~mol} \mathrm{~h}^{-1}\right)$, the outputs from particles to water, soil, and due to degradation become as high as $1.01 \times 10^{-2} \mathrm{~mol} \mathrm{~h}^{-1}$. Thus, the results from the four-fugacity model produce fatal errors: (1) BDE-99 is not mass balanced in both air and aerosols, and (2) the amount of the emission of BDE-99 $\left(1.00 \times 10^{-2} \mathrm{~mol} \mathrm{~h}^{-1}\right)$ to air goes nowhere and at the same time the same amount of output from aerosols originated from nowhere. The exchanges of BDE-99 between air and aerosols are identical with a flux equal to $7.03 \times 10^{-6} \mathrm{~mol} \mathrm{~h}^{-1}$ (almost zero), an equilibrium between air and aerosols, imposed at the cost of the fatal errors described above.

The most reasonable way to solve this crux is simply to allow the emission entering the air at a rate of $0.01 \mathrm{~mol} \mathrm{~h}^{-1}$ to go to aerosols, and then both the air and particles become balanced. However, if this occurs, the chemical can no longer be considered at equilibrium between air and particles. In other words, the crux created by the imposed equilibrium assumption between air and aerosol can be solved by the six-fugacity model as shown in Table 1, in which chemical is in steady-state, not equilibrium, between air and particles.

\subsubsection{Depositions}

The direct consequence of the almost zero air concentration of BDE-99 in the MP Domain predicted by the four-fugacity model (Figs. 5 and 6) is the depositions of gaseous BDE-99. Fig. 11 presents fluxes of BDE-99 between air/aerosols and surfaces (water and soil) at $40{ }^{\circ} \mathrm{C}$ and $-40{ }^{\circ} \mathrm{C}$ as predicted by the four- and the six-fugacity models. When temperature is $40{ }^{\circ} \mathrm{C}$, both models give similar results, while at $-40{ }^{\circ} \mathrm{C}$, the results predicted by the six-fugacity model suggests much higher deposition fluxes from air to water $\left(4.31 \times 10^{-4} \mathrm{~mol} \mathrm{~h}^{-1}\right.$ from six-fugacity model vs. $9.36 \times 10^{-9} \mathrm{~mol} \mathrm{~h}^{-1}$ from four-fugacity model) and from air to soil $\left(3.36 \times 10^{-5} \mathrm{~mol} \mathrm{~h}^{-1}\right.$ from six-fugacity model vs. $1.89 \times 10^{-9} \mathrm{~mol} \mathrm{~h}^{-1}$ from four-fugacity model). In fact, the BDE-99 fluxes between air/aerosols and surfaces (water and soil) at $40{ }^{\circ} \mathrm{C}$ and $-40{ }^{\circ} \mathrm{C}$ predicted by the four-fugacity models are so small that they can be treated as zero.

Fig. 12 presents net fluxes between air and surface and dry and wet depositions of aerosols for BDE-99 in the atmosphere at different temperatures predicted by the four- and six-fugacity models. The difference between the two model predictions for BDE-99 aerosol deposition is not significant, but it is for the BDE-99 gas-phase deposition, especially in the MP Domain. Net air-water and air-soil fluxes of BDE-99 predicted by the four-fugacity model are constant in the MP Domain, and equal to zero, while the fluxes predicted by the six-fugacity model are also constants in the MP 

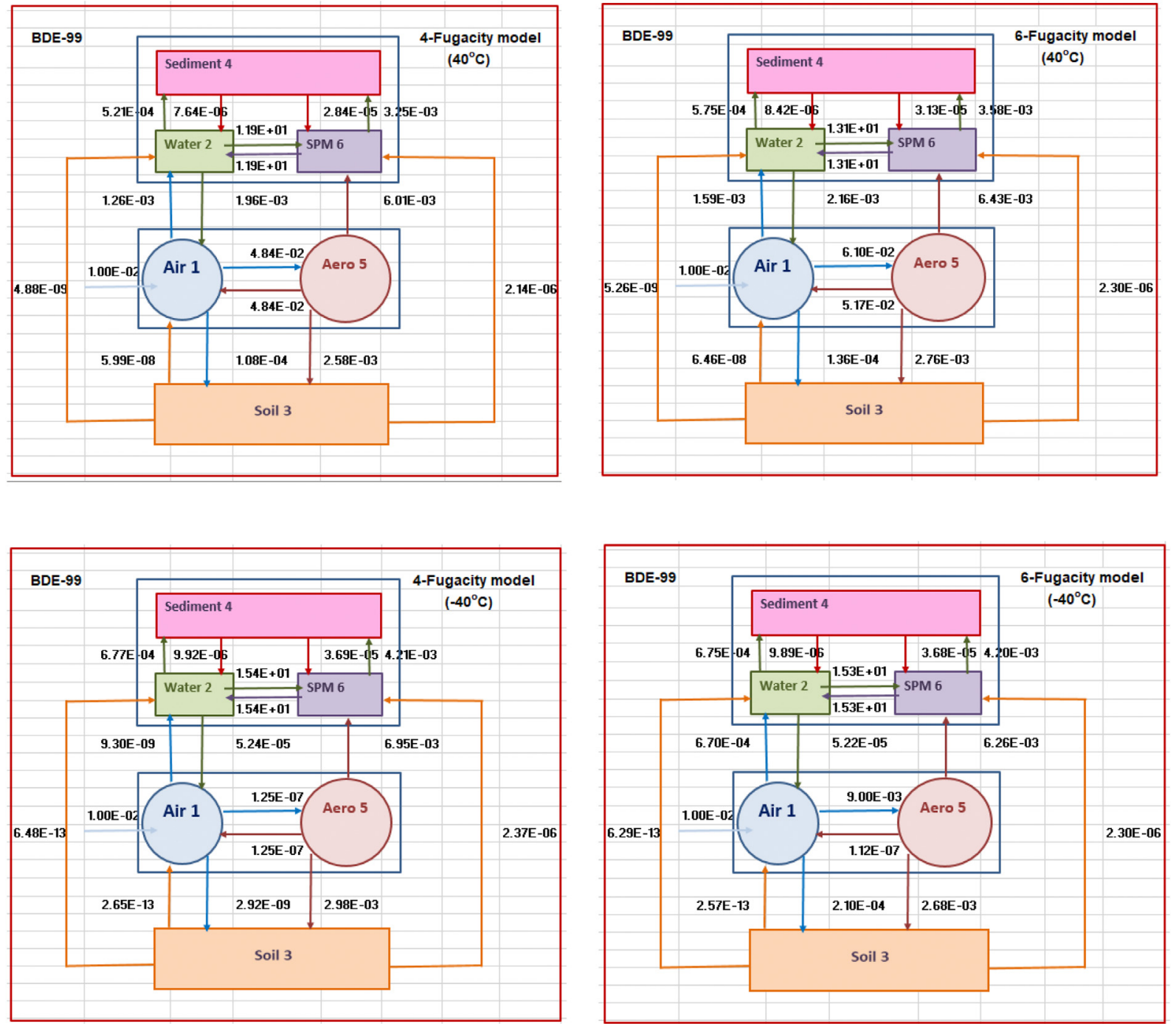

Fig. 8. Flux ( $\mathrm{mol} \mathrm{h}{ }^{-1}$ ) of BDE-99 in the six-compartment system at $40{ }^{\circ} \mathrm{C}$ and $-40{ }^{\circ} \mathrm{C}$ predicted by the two models. Those for other temperatures can be found in Fig. S4, SI.
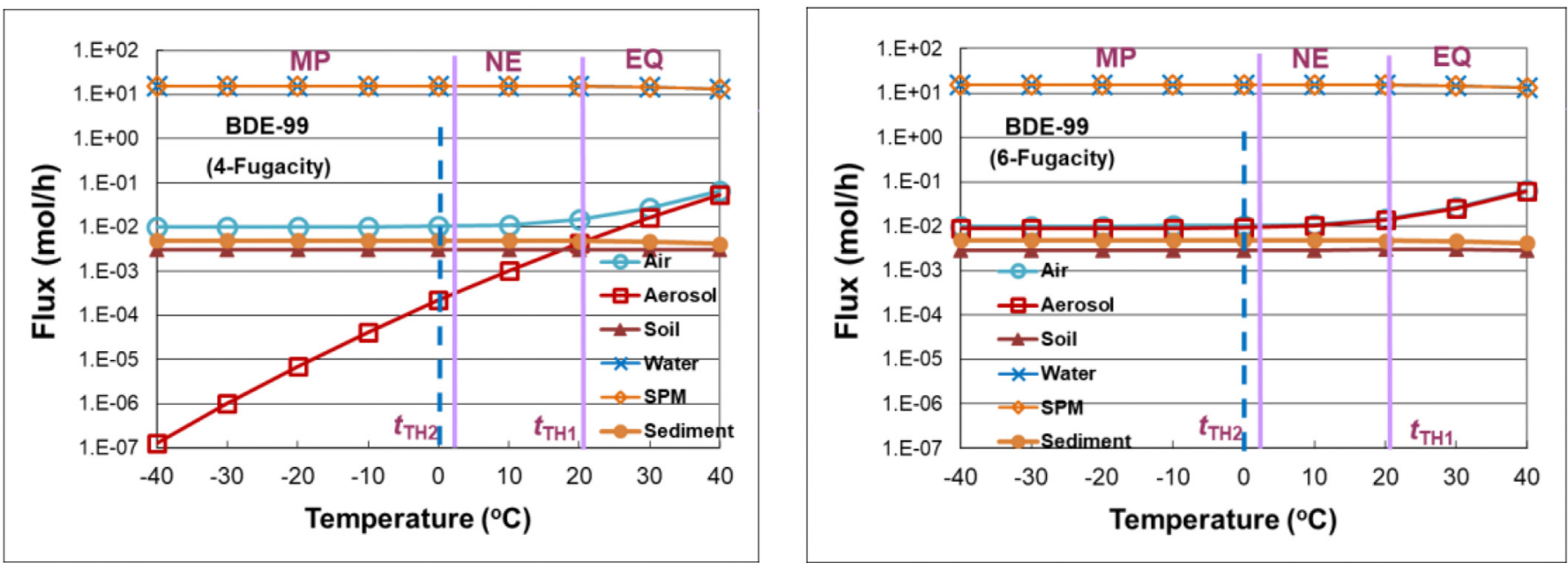

Fig. 9. Input flux $\left(\mathrm{mol} \mathrm{h}^{-1}\right)$ of BDE-99 in the six-compartment system as functions of temperature predicted by the two models. 

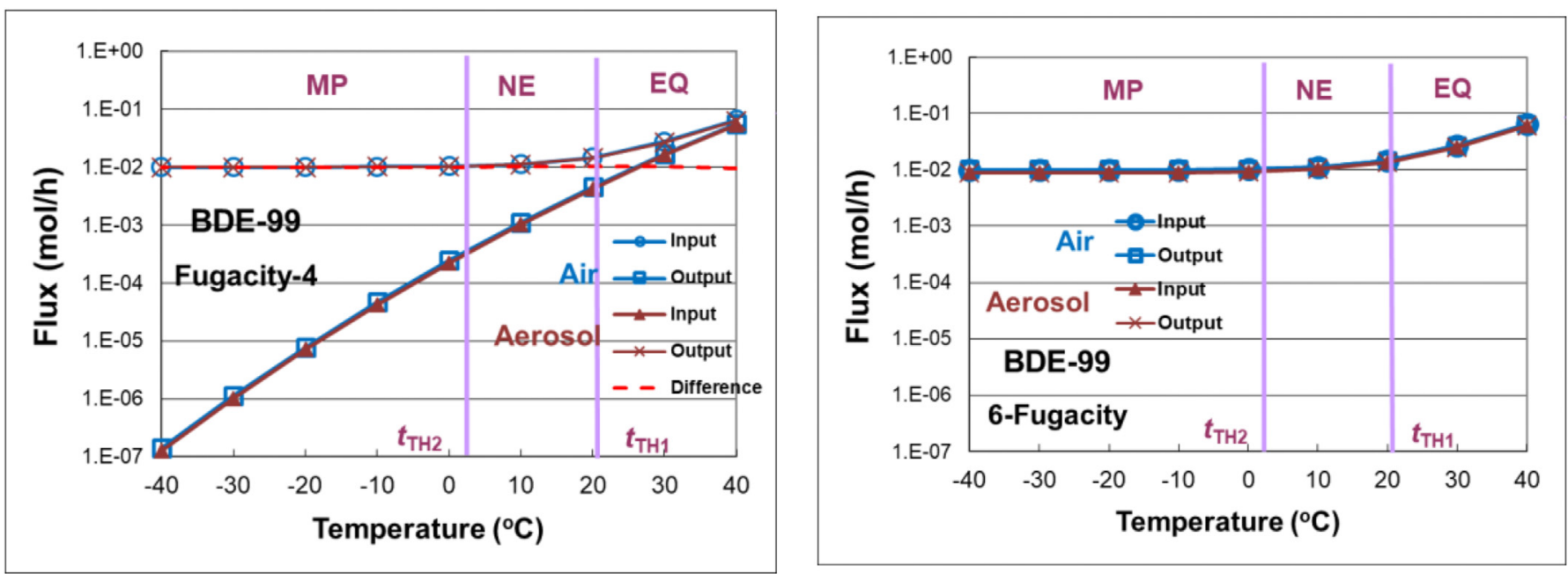

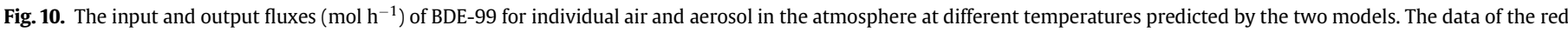

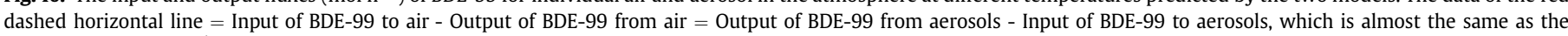
emission $\left(0.01 \mathrm{~mol} \mathrm{~h}^{-1}\right)$. (For interpretation of the references to colour in this figure legend, the reader is referred to the Web version of this article.)

Table 1

The input and output fluxes of BDE-99 for air and aerosol at $-20^{\circ} \mathrm{C}$ predicted by the six-fugacity model.

\begin{tabular}{llllll}
\hline & \multicolumn{2}{l}{ Air } & & \multicolumn{2}{l}{ Aerosol } \\
\cline { 2 - 3 } \cline { 5 - 6 } \cline { 5 - 6 } & Input & Output & & Input & Output \\
\hline Emission & $1.00 \mathrm{E}-02$ & & & \\
Air/Aerosol & $6.29 \mathrm{E}-06$ & $9.00 \mathrm{E}-03$ & & $9.00 \mathrm{E}-03$ & $6.29 \mathrm{E}-06$ \\
Water & $5.22 \mathrm{E}-05$ & $6.70 \mathrm{E}-04$ & & $6.26 \mathrm{E}-03$ \\
Soil & $1.44 \mathrm{E}-11$ & $2.10 \mathrm{E}-04$ & & $2.68 \mathrm{E}-03$ \\
degradation & & $1.76 \mathrm{E}-04$ & & \\
Total & $1.01 \mathrm{E}-02$ & $1.01 \mathrm{E}-02$ & & $9.00 \mathrm{E}-03$ & $9.00 \mathrm{E}-03$ \\
\hline
\end{tabular}

Table 2

The input and output fluxes of BDE-99 for air and aerosol at $-20{ }^{\circ} \mathrm{C}$ predicted by the four-fugacity model.

\begin{tabular}{lccccc}
\hline & \multicolumn{2}{c}{ Air } & & \multicolumn{2}{c}{ Aerosol } \\
\cline { 2 - 3 } \cline { 5 - 6 } & Input & Output & & Input & Output \\
\hline Emission & $1.00 \mathrm{E}-02$ & & & \\
Air/Aerosol & $7.03 \mathrm{E}-06$ & $7.03 \mathrm{E}-06$ & & $7.03 \mathrm{E}-06$ & $7.03 \mathrm{E}-06$ \\
water & $5.27 \mathrm{E}-05$ & $5.23 \mathrm{E}-07$ & & & $6.99 \mathrm{E}-03$ \\
soil & $1.49 \mathrm{E}-11$ & $1.64 \mathrm{E}-07$ & & $3.00 \mathrm{E}-03$ \\
degradation & & $1.38 \mathrm{E}-07$ & & $6.37 \mathrm{E}-05$ \\
Total & $1.01 \mathrm{E}-02$ & $7.85 \mathrm{E}-06$ & & $7.03 \mathrm{E}-06$ & $1.01 \mathrm{E}-02$ \\
\hline
\end{tabular}

Domain, but not equal to zero $\left(6.2 \times 10^{-4} \mathrm{~mol} \mathrm{~h}^{-1}\right.$ from air to water and $2.1 \times 10^{-4} \mathrm{~mol} \mathrm{~h}^{-1}$ from air to soil). This suggests that, in the MP Domain, the four-fugacity model completely excludes gaseous BDE-99 from the exchanges between atmosphere and surfaces (top soil and water bodies).

\section{4. $P / G$ partitioning quotient from monitoring data}

As discussed in Section 3.3, according to the four-fugacity model the PBDEs are in an imposed equilibrium between gaseous and particulate phases in the atmosphere. However, projection by the six-fugacity model, for which these imposed equilibrium conditions are removed, indicates that PBDEs are in steady state between gaseous and particulate phases in the atmosphere, which is verified by the monitoring data measured in Harbin air (Fig. S9). Indeed, steady state, not equilibrium, has been found at other locations including other cities in China, Zurich (Switzerland), Izmir (Turkey), Paris (France), in the Arctic (Li et al., 2015, 2017), and in the Antarctic (Wang et al., 2017).

\section{Implication and discussion}

\subsection{Model results vs monitoring data}

By using the emission data as input to both four- and sixfugacity models, the concentrations of the seven selected PBDE congeners (BDE-28, $-47,-99,-100,-153,-154$, and -209 ) in the atmosphere gas- and particle-phases are estimated from September 2008 to December 2008. As can be seen in Fig. 13 and S8, the concentrations of the selected seven PBDE congeners in the particle-phase and in the soil predicted by these two models are almost identical, and match the monitoring data well. The seven PBDE congeners in the gas-phase, however, differ. As shown in the left panel in Fig. 13, the concentrations of BDE-28 predicted by these two models are almost the same, and match the monitoring data well, but for the remaining congeners, projections by the two models are different, with differences increasing as molecular weights (or bromine number) of the congeners increase. The concentrations for the six congeners in air predicted by the six-fugacity model are consistent with the monitoring data, but this is not the case for the four-fugacity model. BDE-209 provides the best example. The four-fugacity model predicts an air concentration of $10^{-4} \mathrm{pg} \mathrm{m}^{-3}$, which can be considered as zero, while the sixfugacity model predicts $28.4 \mathrm{pg} \mathrm{m}^{-3}$, acceptably close to the monitoring value of $40.0 \mathrm{pg} \mathrm{m}^{-3}$ (Fig. 13).

\subsection{A description for a four-compartment model}

In Fig. 1, if the two compartments in the atmosphere, the air and aerosols, are combined into one compartment "bulk air", and the two compartments in the water body, the water and SPMs, are combined into one compartment "bulk water", we will have the four-compartment system, introduced by Mackay (2001) as the simplest "unit world". Here, data predicted by both models are used to explain the intermedia fluxes among the four compartments, as presented in Fig. S10 for BDE-99 at $40{ }^{\circ} \mathrm{C}$ and $-40{ }^{\circ} \mathrm{C}$. As shown in Fig. S10 and the inputs and outputs for all four compartments, both 

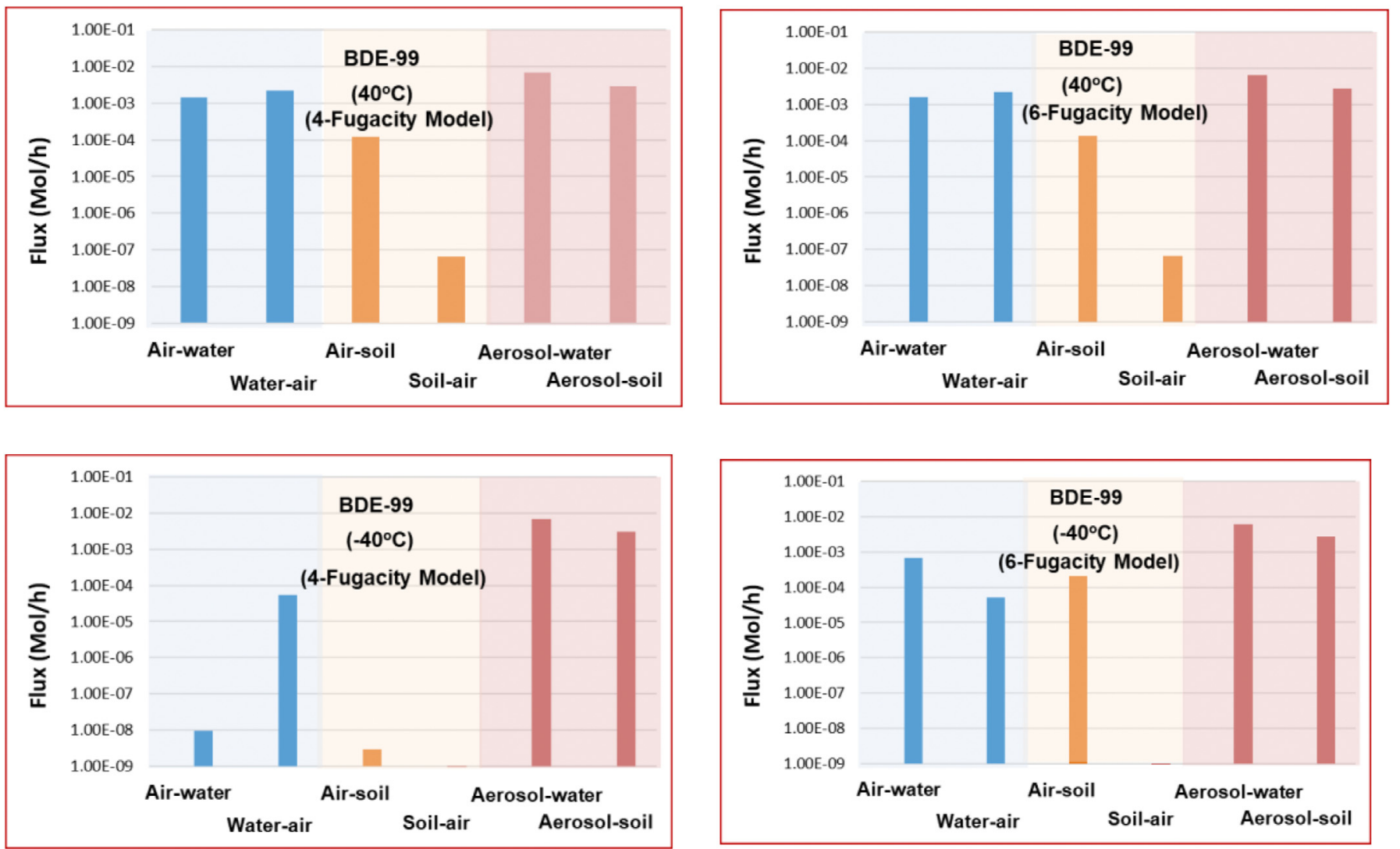

Fig. 11. Depositions $\left(\mathrm{mol} \mathrm{h}^{-1}\right)$ of BDE-99 from air and aerosol to water and soil at two different temperatures $\left(40{ }^{\circ} \mathrm{C}\right.$ and $\left.-40{ }^{\circ} \mathrm{C}\right)$ predicted by the two models.
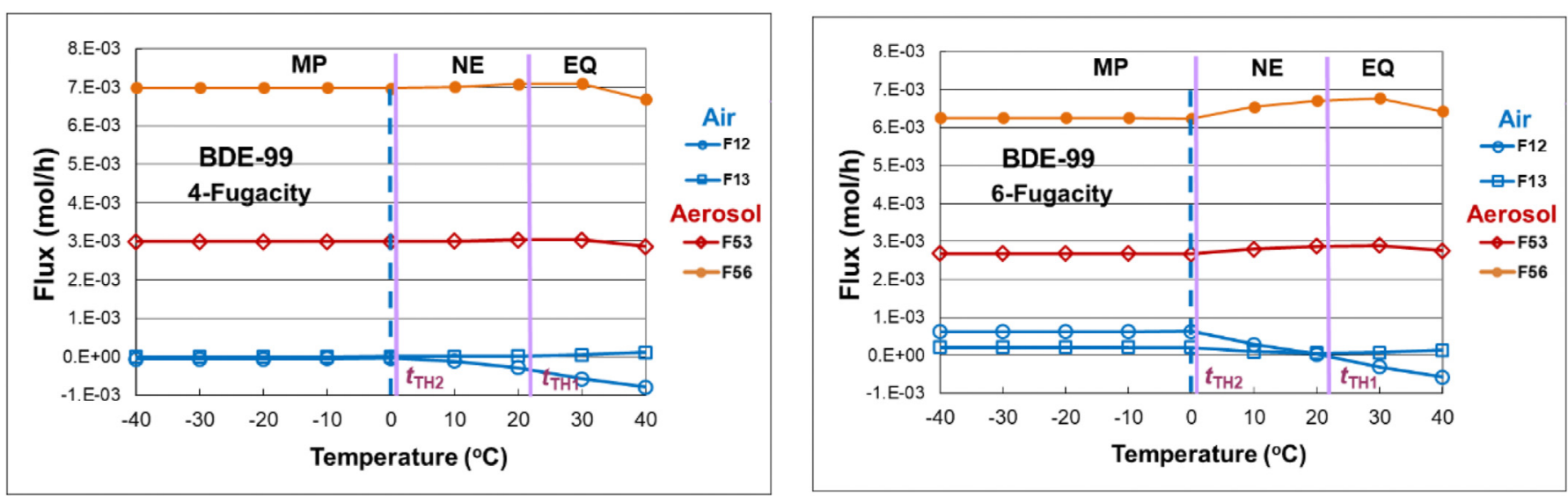

Fig. 12. Dry and wet depositions $\left(\mathrm{mol} \mathrm{h}^{-1}\right)$ of BDE-99 in air and aerosol in the atmosphere at different temperatures predicted by the four- and six-fugacity models.

models give steady state systems with few differences, and masses for all four compartments in each case are balanced. In other words, both models can produce a satisfactory result for the fourcompartment system without considering the intermedia exchange between air and aerosols in the bulk air compartment (Fig. S11). However, as explained previously, only the six-fugacity model can produce a logically consistent steady-state representation for the six-compartment system, as shown in Fig. 3 and in detail described in the following subsections.
5.3. Rule of gaseous chemicals in all intermedia processes in the sixcompartment system

One of the major differences between the projections by the two models relates to the gaseous chemicals. By assuming an equilibrium between gas- and particle-phases in the atmosphere, the fourfugacity model predicts that the concentration of gaseous chemical is actually zero when the values of $K_{\mathrm{OA}}$ are big enough $\left(>10^{11.4}\right)$, while the six-fugacity model, based on the condition of the steady- 

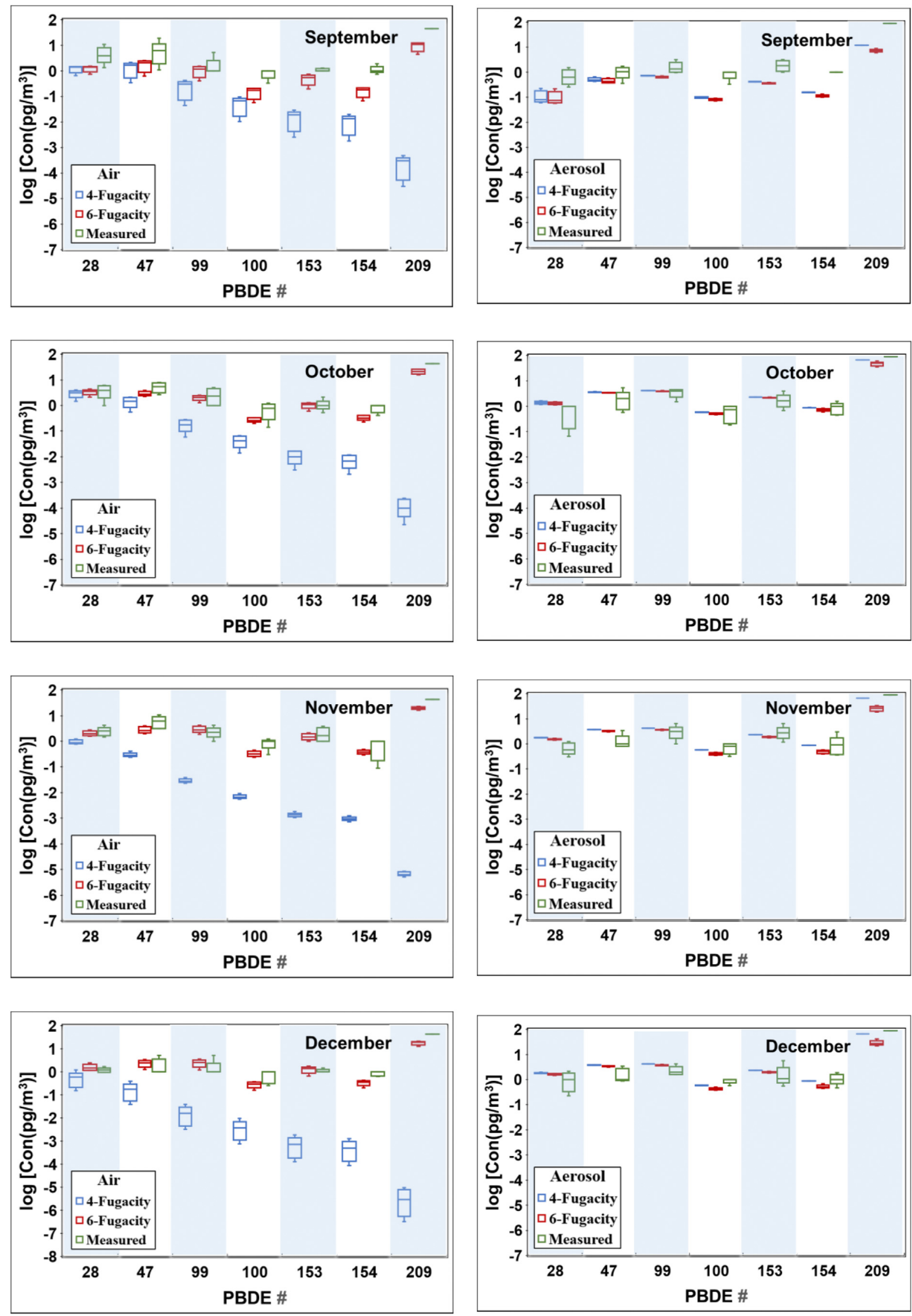

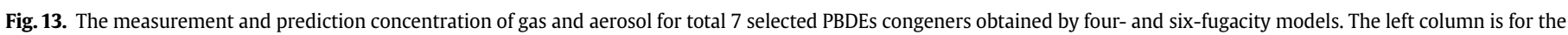
gaseous phase and the right one is for the particulate phase. 
state between gas- and particle-phases in the atmosphere, predict a non-zero amount of chemical remaining in the atmosphere even at high $K_{\mathrm{OA}}$ values. Although the amount remaining in the atmosphere is the lowest among all six compartments, the gaseous chemical comprises the most active and dynamic part in all the intermedia processes. Without the involvement of the gaseous chemical, all the intermedia processes would stop and the whole system would stall. Again, it is this zero concentration of gaseous chemical that renders unacceptable the predictions by the four-fugacity model for the chemicals with high $K_{\mathrm{OA}}$ values or at low temperature.

\subsection{Comparison between six-fugacity model and four-fugacity model}

We believe that the six-fugacity model is superior to the fourfugacity models with the reasons outlined below and also listed in Table S11.

Here, we use BDE-99 as an example to give a general description of the results predicted by the two models in the six-compartment system, as a "unit world". Emission of BDE-99 enters the sixcompartment system with a steady flux of $0.01 \mathrm{~mol} \mathrm{~h}^{-1}$. After a certain time, the whole system attains steady state. The results show that the major difference between the two models is in the atmosphere.

When whole system is in steady-state, as predicted by the sixfugacity model, the fugacities of BDE-99 are not equal between gaseous and particulate phases, indicating no equilibrium between these two phases, whereas the net fluxes of BDE-99 in individual air and aerosol are zero, suggesting a steady state for these two compartments, same as the remaining four compartments in the system.

The drawbacks become intuitively obvious for the results predicted by the four-fugacity model in the MP Domain. The results predicted by the four-fugacity model do not provide a system with a real steady state for the following reasons.

(1) The system cannot be maintained at steady state when the two compartments within the system, air and aerosols, are not in steady state.

(2) A significant amount of BDE-99 $\left(\sim 0.009 \mathrm{~mol} \mathrm{~h}^{-1}\right)$ cannot be mass balanced in the atmosphere within the system. Emissions of BDE-99 enter the atmosphere with a flux of $0.01 \mathrm{~mol} \mathrm{~h}^{-1}$, among which, there is only a small amount sorbed to the aerosols, entering water bodies and top soils by air-surface exchange and wet dissolution, and lost due to degradation, while the rest, which is a significant portion of BDE-99, goes nowhere. At the same time, aerosols need to supply a significant amount of BDE-99 to support water and soil depositions, with its origin not being specified by the model. It is reasonable to think that this significant amount of BDE-99 in air should be sorbed to aerosols, and then the entire system would be in steady state, which, however, violates the assumption of the equilibrium between the gasand particle-phases.

Therefore, the predictions by the four-fugacity model are problematic and unacceptable.

Now we can answer the two questions raised in the Introduction. (1) Chemicals are in steady state and equilibrium between water and SPMs, but in a steady state and not necessary an equilibrium, between air and aerosols. (2) Current level III model results cannot be considered a true representation of steady state for the entire system.

\section{Credit author statement}

Yi-Fan Li: Conceptualization, Methodology, Supervision, Writing- Original draft preparation, Writing- Reviewing and Editing. Meng Qin: Methodology, Software, Data curation, Visualization, Writing- Reviewing and Editing, Investigation. Pu-Fei Yang: Data curation, Visualization, Investigation, Writing- Reviewing and Editing. Li-Yan Liu: Writing- Reviewing and Editing, Investigation. Lin-Jun Zhou: Writing- Reviewing and Editing, Investigation. JiNing Liu: Writing- Reviewing and Editing Investigation. Li-Li Shi: Writing- Reviewing and Editing, Investigation. Li-Na Qiao: WritingReviewing and Editing. Peng-Tuan Hu: Writing- Reviewing and Editing. Chong-Guo Tian: Writing- Reviewing and Editing, Investigation. Anatoly Nikolaev: Writing- Reviewing and Editing, , Investigation. Robie Macdonald: Methodology, Writing- Reviewing and Editing, Investigation

\section{Declaration of competing interest}

The authors declare that they have no known competing financial interests or personal relationships that could have appeared to influence the work reported in this paper.

\section{Acknowledgement}

This work was supported by the National Key Research and Development Program of China (2018YFC1801504), Polar Academy, Harbin Institute of Technology (No. PA-HIT-201901), and State Key Laboratory of Urban Water Resource and Environment (Harbin Institute of Technology) (No. 2019DX04).

\section{Appendix A. Supplementary data}

Supplementary data to this article can be found online at https://doi.org/10.1016/j.chemosphere.2021.129580.

\section{References}

Arnot, J.A., Mackay, D., 2008. Policies for chemical hazard and risk priority setting: can persistence, bioaccumulation, toxicity, and quantity information Be combined? Environ. Sci. Technol. 42, 4648-4654. https://doi.org/10.1021/ es800106g.

Besis, A., Lammel, G., Kukucka, P., Samara, C., Sofuoglu, A., Dumanoglu, Y., Eleftheriadis, K., Kouvarakis, G., Sofuoglu, S.C., Vassilatou, V., Voutsa, D., 2017. Polybrominated diphenyl ethers (PBDEs) in background air around the Aegean: implications for phase partitioning and size distribution. Environ. Sci. Pollut. Control Ser. 24, 28102-28120. https://doi.org/10.1007/s11356-017-0285-7.

Beyer, A., Mackay, D., Matthies, M., Wania, F., Webster, E., 2000. Assessing longrange transport potential of persistent organic pollutants. Environ. Sci. Technol. 34, 699-703. https://doi.org/10.1021/es990207w.

Cao, R., Zhang, H., Zhao, L., Zhang, Y., Geng, N., Teng, M., Zou, L., Gao, Y., Ni, Y., Fu, Q., Chen, J., 2018. Hazy weather-induced variation in environmental behavior of $\mathrm{PCDD} / \mathrm{fs}$ and PBDEs in winter atmosphere of A north China megacity. Environ. Sci. Technol. 52, 8173-8182. https://doi.org/10.1021/acs.est.8b02148.

Dale, A.L., Casman, E.A., Lowry, G.V., Lead, J.R., Viparelli, E., Baalousha, M., 2015a. Modeling nanomaterial environmental fate in aquatic systems. Environ. Sci. Technol. 49, 2587-2593. https://doi.org/10.1021/es505076w.

Dale, A.L., Lowry, G.V., Casman, E.A., 2015b. Stream dynamics and chemical transformations control the environmental fate of silver and zinc oxide nanoparticles in a watershed-scale model. Environ. Sci. Technol. 49, 7285-7293. https:// doi.org/10.1021/acs.est.5b01205.

Di Guardo, A., Gouin, T., MacLeod, M., Scheringer, M., 2018. Environmental fate and exposure models: advances and challenges in 21st century chemical risk assessment. Environ. Sci.-Process Impacts 20, 58-71. https://doi.org/10.1039/ c7em00568g.

Diamond, M.L., Priemer, D.A., Law, N.L., 2001. Developing a multimedia model of chemical dynamics in an urban area. Chemosphere 44, 1655-1667. https:// doi.org/10.1016/s0045-6535(00)00509-9.

Harner, T., Bidleman, T.F., 1998. Octanol-air partition coefficient for describing particle/gas partitioning of aromatic compounds in urban air. Environ. Sci. Technol. 32 (10), 1494-1502. https://doi.org/10.1021/es970890r.

Jiang, L., Gao, W., Ma, X., Wang, Y., Wang, C., Li, Y., Yang, R., Fu, J., Shi, J., Zhang, Q., Wang, Y., Jiang, G., 2020. Long-term investigation of the temporal trends and 
gas/particle partitioning of short- and medium-chain chlorinated paraffins in ambient air of king george island, Antarctica. Environ. Sci. Technol. https:// doi.org/10.1021/acs.est.0c05964.

Li, L., Westgate, J.N., Hughes, L., Zhang, X., Givehchi, B., Toose, L., Armitage, J.M., Wania, F., Egeghy, P., Arnot, J.A., 2018. A model for risk-based screening and prioritization of human exposure to chemicals from near-field sources. Environ. Sci. Technol. 52, 14235-14244. https://doi.org/10.1021/acs.est.8b04059.

Li, W.-L., Liu, L.-Y., Song, W.-W., Zhang, Z.-F., Qiao, L.-N., Ma, W.-L., Li, Y.-F., 2016a. Five-year trends of selected halogenated flame retardants in the atmosphere of Northeast China. Sci. Total Environ. 539, 286-293. https://doi.org/10.1016/ j.scitotenv.2015.09.001.

Li, W.L., Huo, C.Y., Liu, L.Y., Song, W.W., Zhang, Z.F., Ma, W.L., Qiao, L.N., Li, Y.F., 2016b. Multi-year air monitoring of legacy and current-use brominated flame retardants in an urban center in northeastern China. Sci. Total Environ. 571, 633-642.

Li, Y.F., Qiao, L.-N., Ren, N.-Q. Macdonald, R.W., Kannan, K., 2020. Gas/particle partitioning of semi-volatile organic compounds in the atmosphere: transition from unsteady to steady state. Sci. Total Environ. 710, 136394. https://doi.org/ 10.1016/j.scitotenv.2019.136394.

Li, Y.F., Ma, W.L., Yang, M., 2015. Prediction of gas/particle partitioning of polybrominated diphenyl ethers (PBDEs) in global air: a theoretical study. Atmos. Chem. Phys. 15, 1669-168110.

Li, Y.F., Qiao, L.N., Ren, N.Q., Sverko, E., Mackay, D., Macdonald, R.W., 2017. Decabrominated diphenyl ethers (BDE-209) in Chinese and global air: levels, gas/ particle partitioning, and long-range transport: is long-range transport of BDE209 really governed by the movement of particles? Environ. Sci. Technol. 51, 1035-1042. https://doi.org/10.1021/acs.est.6b05395.

Mackay, D., 2001. Multimedia Environmental Models - the Fugacity Approach, the second ed. CRC Press LLC, 2000 N.W. Corporate Blvd., Boca Raton, Florida 33431.

Mackay, Donald, Celsie, Alena K.D., Parnis, J. Mark, 2019. Kinetic delay in partitioning and parallel particle pathways: underappreciated aspects of environmental transport. Environ. Sci. Technol. 53 (1), 234-241. https://doi.org/ 10.1021/acs.est.8b04514.

Mackay, D., Di Guardo, A., Paterson, S., Cowan, C.E., 1996. Evaluating the environmental fate of a variety of types of chemicals using the EQC model. Environ. Toxicol. Chem. 15, 1627-1637. https://doi.org/10.1002/etc.5620150930.

Mackay, D., Paterson, S., 1981. Calculating fugacity. Environ. Sci. Technol. 15, 1006-1014. https://doi.org/10.1021/es00091a001.

Mackay, D., Paterson, S., 1991. Evaluating the multimedia fate OF organic-chemicals
- a level-III fugacity model. Environ. Sci. Technol. 25, 427-436. https://doi.org/ 10.1021/es00015a008.

Pankow, J.F., Bidleman, T.F., 1991. Effects of temperature, TSP and per cent nonexchangeable material in determining the gas-particle partitioning of organic compounds. Atmos. Environ. Part A. General Topics 25, 2241-2249. https:/ doi.org/10.1016/0960-1686(91)90099-s.

Parnis, J.M., Taskovic, T., Celsie, A.K.D., Mackay, D., 2020. Indoor dust/air partitioning: evidence for kinetic delay in equilibration for low-volatility SVOCs. Environ. Sci. Technol. 54, 6723-6729. https://doi.org/10.1021/acs.est.0c00632.

Qiao, L.-N., Zhang, Z.-F., Liu, L.-Y., Song, W.-W., Ma, W.-L., Zhu, N.-Z., Li, Y.-F., 2019. Measurement and modeling the gas/particle partitioning of organochlorine pesticides (OCPs) in atmosphere at low temperatures. Sci. Total Environ. 667, 318-324. https://doi.org/10.1016/j.scitotenv.2019.02.347.

Scheringer, M., 1996. Persistence and spatial range as endpoints of an exposurebased assessment of organic chemicals. Environ. Sci. Technol. 30, 1652-1659. https://doi.org/10.1021/es9506418.

Wang, P., Li, Y., Zhang, Q., Yang, Q., Zhang, L., Liu, F., Fu, J., Meng, W., Wang, D., Sun, H., Zheng, S., Hao, Y., Liang, Y., Jiang, G., 2017. Three-year monitoring of atmospheric PCBs and PBDEs at the Chinese Great Wall Station, West Antarctica: levels, chiral signature, environmental behaviors and source implication. Atmos. Environ. 150, 407-416. https://doi.org/10.1016/ j.atmosenv.2016.11.036.

Wania, F., Mackay, D., 1993. Modelling the global distribution of toxaphene: a discussion of feasibility and desirability. Chemosphere 27, 2079-2094. https:// doi.org/10.1016/0045-6535(93)90403-r.

Wania, F., Mackay, D., 1995. A global distribution model for persistent organic chemicals. Sci. Total Environ. 160, 211-232. https://doi.org/10.1016/00489697(95)04358-8.

Weschler, C.J., Nazaroff, W.W., 2010. SVOC partitioning between the gas phase and settled dust indoors. Atmos. Environ. 44, 3609-3620. https://doi.org/10.1016 j.atmosenv.2010.06.029.

Yamasaki, H., Kuwata, K., Miyamoto, H., 1982. Effects of ambient temperature on aspects of airborne polycyclic aromatic hydrocarbons. Environ. Sci. Technol. 16, 189-194.

Zhang, Q.-Q., Ying, G.-G., Chen, Z.-F., Liu, Y.-S., Liu, W.-R., Zhao, J.-L., 2015. Multimedia fate modeling and risk assessment of a commonly used azole fungicide climbazole at the river basin scale in China. Sci. Total Environ. 520, 39-48. https://doi.org/10.1016/j.scitotenv.2015.03.038. 